\title{
Efficacy of phentolamine mesylate in reducing the duration of various local anesthetics
}

\author{
Alejandro Gago-García', Cayetana Barrilero-Martin', Miguel Ángel Alobera-Gracia', Mariano del Canto-Pingarrón', \\ Jesús Seco-Calvo² \\ 'University of León, León, Spain \\ ${ }^{2}$ Institute of Biomedicine (IBIOMED), University of León, León, Spain; Visiting Researcher of University of the Basque Country (UPV/EHU), \\ Leoia, Spain
}

\begin{abstract}
Background: To evaluate changes in the effectiveness of phentolamine mesylate in combination with different local anesthetics (LAs) and vasoconstrictors. A prospective randomized double-blind study was conducted with 90 patients divided into three groups, with each group being administered one of three different LAs: lidocaine $2 \% 1 / 80,000$, articaine $4 \% 1 / 200,000$, and bupivacaine $0.5 \% 1 / 200,000$.

Methods: We compared treatments administered to the mandible involving a LA blockade of the inferior alveolar nerve. Results were assessed by evaluating reduction in total duration of anesthesia, self-reported patient comfort using the visual analog pain scale, incidence rates of the most common adverse effects, overall patient satisfaction, and patient feedback.

Results: The differences among the three groups were highly significant $(\mathrm{P}<0.001)$; time under anesthesia was especially reduced for both the lip and tongue with bupivacaine. The following adverse effects were reported: pain at the site of the anesthetic injection $(11.1 \%)$, headaches $(6.7 \%)$, tachycardia $(1.1 \%)$, and heavy bleeding after treatment (3.3\%). The patients' feedback and satisfaction ratings were $100 \%$ and $98.9 \%$, respectively. Conclusions: Efficient reversal of LAs is useful in dentistry as it allows patients to return to normal life more readily and avoid common self-injuries sometimes caused by anesthesia. Phentolamine mesylate reduced the duration of anesthesia in the three studied groups, with the highest reduction reported in the bupivacaine group (from $460 \mathrm{~min}$ to $230 \mathrm{~min}$ for the lip and $270 \mathrm{~min}$ for the tongue $[\mathrm{P}<0.001]$ ).
\end{abstract}

Keywords: Articaine; Bupivacaine; Epinephrine; Lidocaine; Local Anesthesia; Phentolamine Mesylate.

This is an Open Access article distributed under the terms of the Creative Commons Attribution Non-Commercial License (http://creativecommons.org/licenses/by-nc/4.0/) which permits unrestricted non-commercial use, distribution, and reproduction in any medium, provided the original work is properly cited.

\section{INTRODUCTION}

Local anesthetics (LAs) interrupt neuronal conduction by inhibiting the influx of sodium ions through channels or ionophores in the neuronal membranes. Anesthetics target receptors found inside these sodium channels more readily when they are either in an activated or deactivated state than at rest. This may explain why different anesthetics preferentially affect specific types of neuronal fibers [1].

However, lack of control over the total duration of LA frequently causes secondary effects in children and adults: perceptive (altered physical appearance), sensory (lack of sensation), and functional (reduced ability to speak, smile, gesticulate, drink, and/or control drooling), as well as the unpleasant persistent sensation caused by residual anesthesia after treatment [2-4].

These secondary effects can also result in patients accidentally biting the oral mucosa, tongue, or lips, which

Received: October 23, 2020 • Revised: December 30, 2020 - Accepted: January 3, 2021

Corresponding Author: Alejandro Gago García, University of León, Centro de formación COFIL c/Alfonso IX, 1324004 León, León, Spain

Phone: +34669198249 E-mail: alejandrogagogarcia@gmail.com

Copyright(C) 2021 Journal of Dental Anesthesia and Pain Medicine 


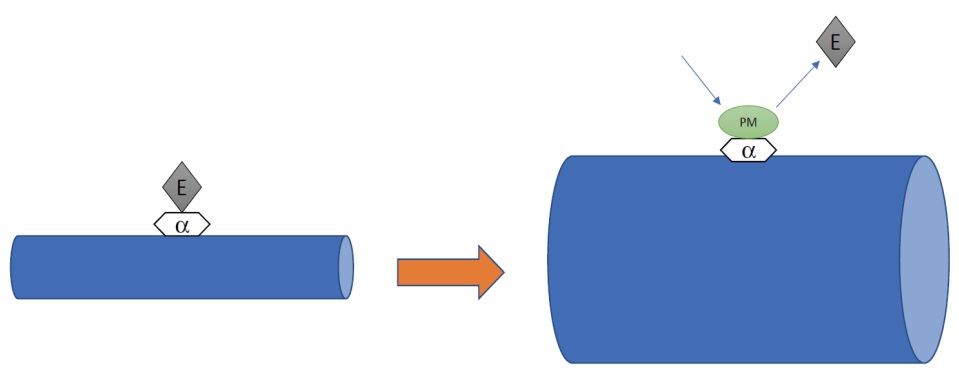

Fig. 1. Hypothetical mechanism of action of phentolamine mesylate: epinephrine (E) binds to the a-adrenergic receptor, resulting in vasocontraction. Phentolamine mesylate (PM) competitively binds to the a-adrenergic receptor, causing vasodilatation.

can further interfere with readjustment to normal life.

Phentolamine mesylate is a safe, injectable solution, packaged in individual cartridges and approved by the Food and Drug Administration for the reversal of anesthesia in the lips and tongue after use of LA-containing vasoconstrictors [5-12].

This drug has been previously used to aid the diagnosis of pheochromocytoma and treat erectile dysfunction, dermal necrosis, and several hypertension conditions $[8,13,14]$.

However, phentolamine mesylate is a pregnancy risk category $\mathrm{C}$ drug, and whether the drug is secreted in breast milk in lactating patients is unknown. Therefore, its use is generally avoided to prevent potential adverse effects [12].

The mechanism by which phentolamine mesylate accelerates the reversal of soft tissue anesthesia and associated functional deficits is not fully understood. It has been proposed to be an alpha-adrenergic antagonist, which blocks the vasoconstriction associated with epinephrine that is also used in dental anesthetic formulations. This enhances the systemic absorption of the local anesthetic from the injection site (Fig. 1) $[2,4,13,14]$.

Following administration, phentolamine mesylate is $100 \%$ available from the intraoral submucosal injection site and peak concentrations are achieved 10-20 min after injection. Systemic phentolamine exposure increases linearly after intraoral submucosal injection of $0.8 \mu \mathrm{g}$ compared to a dose of $0.4 \mu \mathrm{g}$. The terminal elimination half-life of phentolamine in the blood is approximately
2-3 hours. The pharmacokinetics of phentolamine mesylate in adults and children over $30 \mathrm{~kg}$ are similar after intraoral submucosal injection $[3,7,12,13,15]$.

Based on these findings, the working hypothesis was that phentolamine mesylate is an effective method for reversing local anesthesia in dentistry, especially when combined with bupivacaine. Therefore, the null hypothesis was that phentolamine mesylate is not effective in reversing local anesthesia in dentistry, and no difference among reversal of various anesthetics exists.

The objective of the present study was to determine the extent of reduction in the duration of anesthesia that could be achieved with phentolamine mesylate when combined with three different LAs, compared to the average duration of anesthesia for each LA. Additionally, the reduction in duration of anesthesia was compared for all three anesthetics.

\section{METHODS}

\section{Ethics}

The study protocol was approved by the Ethics Committee of the University of León (Spain) on September 9, 2016, under registration number ÉTICA ULE 0082016 and was recorded at https://clinicaltrials.gov/ under registration number NCT03740386.

\section{Participants}

A prospective randomized double-blind clinical trial 
Table 1. Descriptive and comparative analysis of sociodemographic patient characteristics, stratified by type of anesthetic used

\begin{tabular}{|c|c|c|c|c|c|c|}
\hline \multirow[b]{2}{*}{ Variable } & \multirow{2}{*}{$\begin{array}{l}\text { Total sample } \\
\text { (n = 90) }\end{array}$} & \multicolumn{3}{|c|}{ Groups based on anesthesia used } & \multicolumn{2}{|c|}{ Statistical test } \\
\hline & & $\begin{array}{l}\text { Lidocaine } \\
(n=30)\end{array}$ & $\begin{array}{l}\text { Articaine } \\
(n=30)\end{array}$ & $\begin{array}{l}\text { Bupivacaine } \\
(\mathrm{n}=30)\end{array}$ & Value & $P$ \\
\hline Sex $F$ & $55.6 \% \quad(50)$ & $60.0 \%(18)$ & $53.3 \%(16)$ & $53.3 \%(16)$ & $\mathrm{Chi}^{2}=0.36^{\mathrm{NS}}$ & .835 \\
\hline M & $44.4 \% \quad(40)$ & $40.0 \%(12)$ & $46.7 \%(14)$ & $46.7 \%$ (14) & & \\
\hline Age (Median e.d.) & $44.3( \pm 11.0)$ & $44.0( \pm 11.2)$ & $47.1( \pm 11.2)$ & $41.8( \pm 10.3)$ & $\mathrm{F}=1.82^{\mathrm{NS}}$ & .168 \\
\hline$\leq 44 \mathrm{yr}$ & $52.2 \%(47)$ & $53.3 \%(16)$ & $46.7 \%(14)$ & $56.7 \%(17)$ & $\mathrm{Chi}^{2}=0.62^{\mathrm{NS}}$ & .732 \\
\hline$\geq 45 \mathrm{yr}$ & $47.8 \%(43)$ & $46.7 \%(14)$ & $53.3 \%(16)$ & $43.3 \% \quad(13)$ & & \\
\hline
\end{tabular}

NS, not significant. $(P>.05)$

was conducted with 123 individuals at our clinic. Finally, data of 90 individuals were analyzed.

An a priori sample size calculation was used to estimate the number of patients required for testing differences among independent groups using $\mathrm{G}^{*}$ Power 3.1.9.2 (Dusseldorf University, Germany; as recommended by Faul et al. [16]). We considered the difference in values found in a pilot study $(n=10)$ with two groups of ten patients conducted by Calvo-Lobo et al. [17] with an $\alpha$ error of 0.05 and a $\beta$ error of 0.20 . This calculation indicated that at least 27 patients were required in each group (81 patients). Assuming a dropout rate of $10 \%$, the minimum sample size was set at $\mathrm{n}=90$.

After application of the inclusion and exclusion criteria, 90 participants were assigned an allocation number using a block randomization scheme. Demographic characteristics of the groups are detailed in Table 1. Patients were randomly assigned to the following groups using the QuickCalcs application in GraphPad (GraphPad Software Inc., San Diego, CA, USA): Group 1, lidocaine $2 \% 1 / 80000(\mathrm{n}=30)$; Group 2, articaine 4\% 1/200000 $(\mathrm{n}=30)$; and Group 3, bupivacaine 0.5\% 1/200000 (n = 30). Enrolment was voluntary and written informed consent was obtained from all participants. Further, non-discriminatory selection criteria were applied. The recruitment and allocation process is shown in Fig. 2.

\section{Inclusion criteria}

Patients who weighed over $30 \mathrm{~kg}$ and were older than 18 years, in good health, and not currently taking any medications that would alter pain perception, as determined using their medical and oral health records, were enrolled.

\section{Exclusion criteria}

The exclusion criteria were as follows: liver or kidney disease; ongoing fertility treatment, currently pregnant or breastfeeding; a history of significant medical conditions (Class II or higher per the American Society of Anesthesiologists); ongoing oral anticoagulants; allergies to anesthetics, excipients, or phentolamine mesylate; previous facial paresthesia or altered facial sensitivity; administration of painkillers or anti-inflammatory medication the previous day that could interfere with their perception of sensitivity or pain assessment; active oral pathologies; not candidates for regular anesthetic techniques or require more than one anesthesia cartridge; incapable of providing informed consent; requiring treatment lasting more than $60 \mathrm{~min}$; and any acute painful or infectious process.

\section{Intervention procedure}

The following treatment protocols were performed: tooth filling, tooth extraction, full mouth disinfection, implant placement, and root canal treatment.

We analyzed results only for the lower jaw using the inferior alveolar nerve block technique, as the sensation caused by infiltration in the upper jaw is more ambiguous and difficult for patients to describe because it can affect other structures by diffusion. By focusing on the lower jaw, anesthesia always remains concentrated in a particular location including the inferior alveolar nerve 


\section{CONSORT 2010 Flow Diagram}

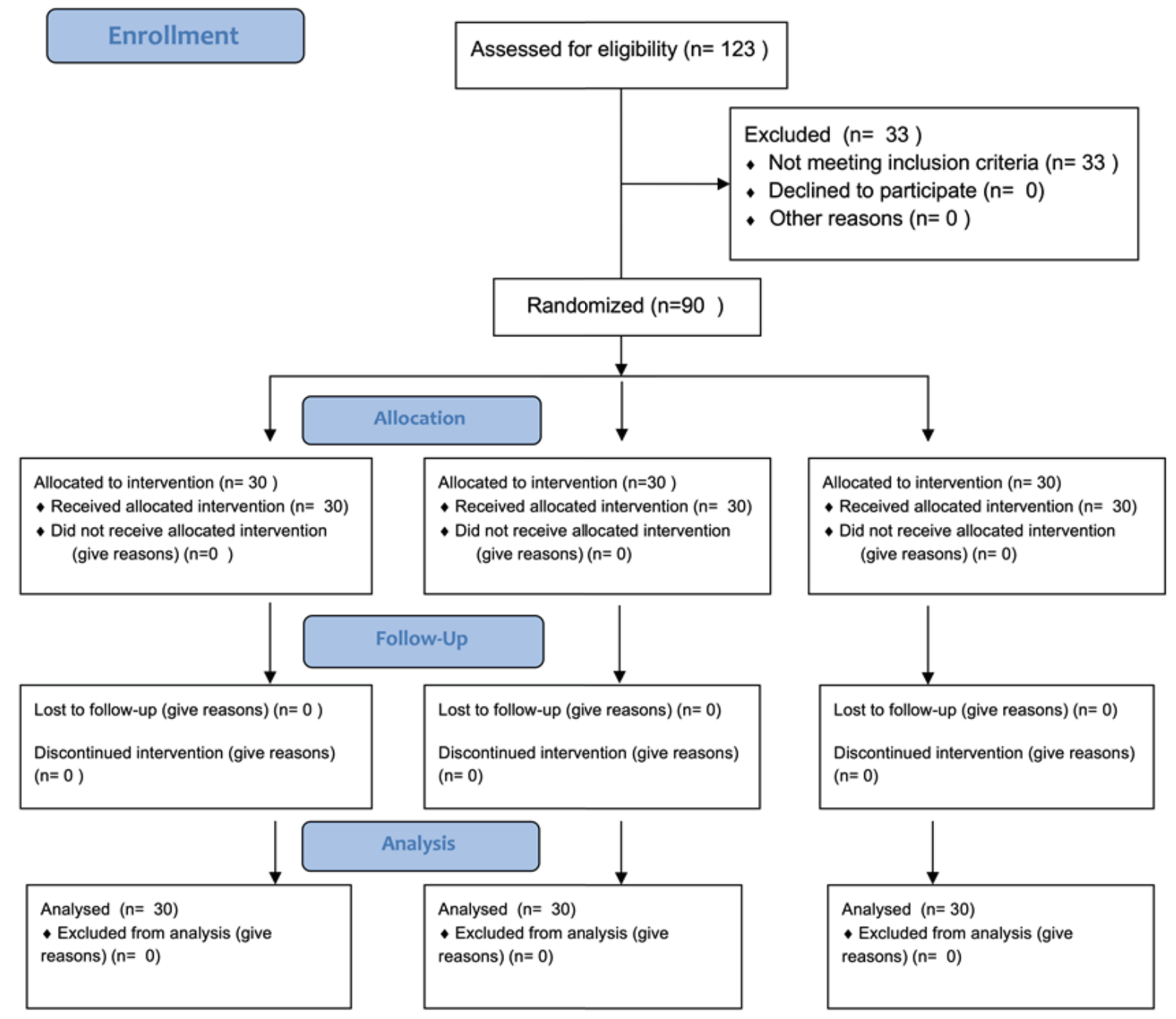

Fig. 2. Flowchart depicting the participant recruitment and allocation process

and lingual nerve of the anesthetized hemiarch.

Local anesthesia of the inferior alveolar nerve was performed using a direct technique with a $27-\mathrm{G} \times 38-\mathrm{mm}$ needle and minimal use of anesthesia in the buccal area so as not to interfere with the buccal nerve or the mental region. The control was the other side where no anesthesia was administered. The recommended phentolamine mesylate dose was based on the number of cartridges of LA administered with the vasoconstrictor. The phentolamine mesylate cartridge was administered after each treatment was completed using the same needle size and technique and to the location where the anesthesia was previously deposited. The maximum recommended phentolamine mesylate dose in adults is two cartridges, and the proportion of anesthesia to reversal agent was always 1:1 [12].

The following parameters were recorded for all groups:

1) Total duration of LA in the soft tissues of the lip and tongue, recorded in 15-min increments, with patients describing sensations in the lip and tongue until numbness had completely disappeared in both.

2) Visual analog pain scale

3) Type of treatment performed

4) Most frequent adverse effects (pain at the site of injection, headache, and tachycardia)

5) Patient satisfaction and likelihood of recommending 
Table 2. Descriptive and comparative analysis of treatment performed, stratified according to the type of anesthetic used

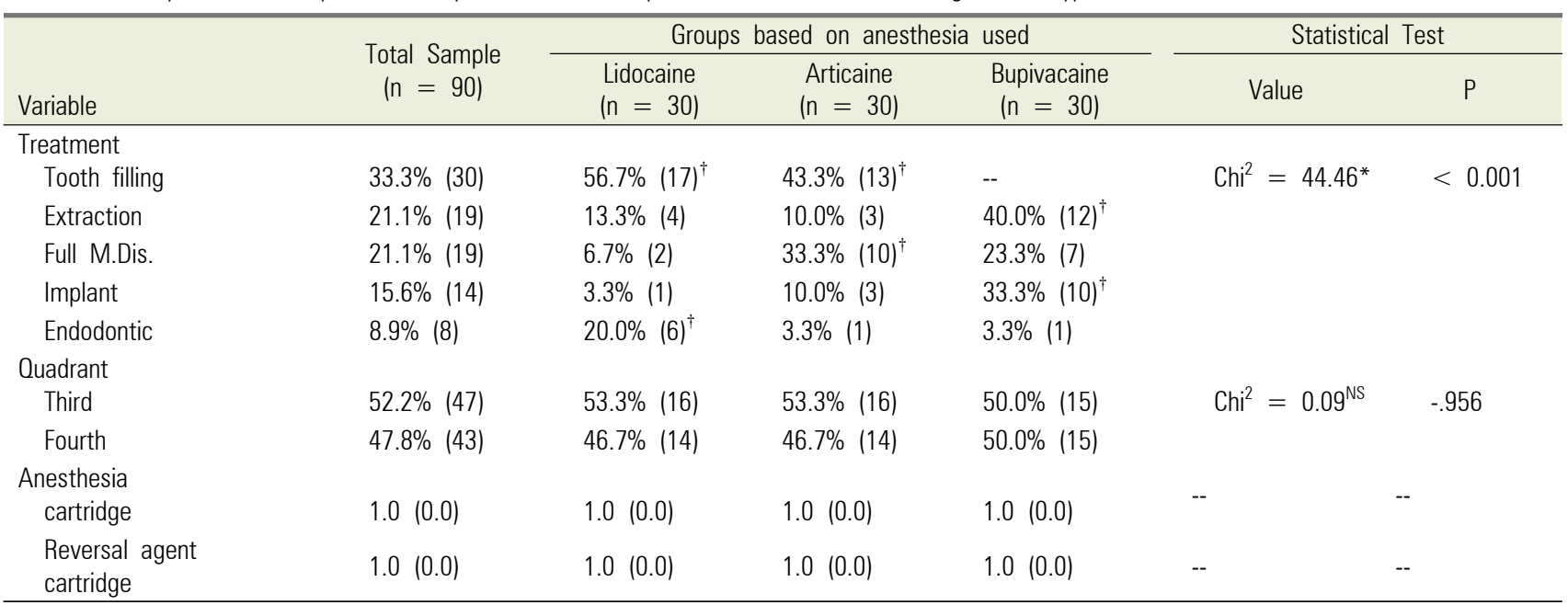

Full M Dis, full mouth disinfection; NS, not significant $(P>.05)$.

* Highly significant $(P<.01)$

$\dagger$ Indicate significance (residue $=>2$ )

treatment, assessed using a questionnaire

6) Heavy bleeding after treatment (bleeding for more than $5 \mathrm{~min}$ after completion of the treatments prone to bleeding)

Patients were instructed to mark the corresponding box for each 15-min interval after injection of the reversal agent, indicating the sensation felt during each interval: 1) numbed, 2) tingling, or 3) normal.

Additionally, the Heft-Parker visual analog scale [18] from 0 (no pain) to 10 (most severe pain possible) was administered. This scale was used to record the postoperative pain experienced by the patient. This document also included a questionnaire on patient's overall satisfaction and whether they would recommend the treatment.

\section{Statistical analysis}

For statistical analysis, the IBM-SPSS-22 software was used (IBM Corp., Armonk. NY. USA).

The following statistical techniques and tests were used: for (nominal) qualitative variables, frequency distributions and percentages; for quantitative variables, data exploration using a $\mathrm{Q}^{-} \mathrm{Q}$ plot with normal distribution, histogram, asymmetry coefficient, and kurtosis/height, along with the Kolmogorov-Smirnov (KS) test and descriptive analysis using standard measures (mean, median for central tendency, standard deviation, range, and interquartile range for variability). The Chi-square test was used to compare categorical variables. The Kruskal-Wallis and Mann-Whitney tests were used to compare the quantitative variables of each group. Further, the effect size was estimated. The Student's t-test was used to compare empirical values with a specific value. The level of significance was 5\% (P< 0.05), except for the KS test, wherein only highly significant values $(\mathrm{P}<0.01)$ were considered.

The mean duration of anesthesia was determined from previous literature [19-21] and subsequently compared with the durations estimated by the manufacturers. Finally, the following values were used in the analysis: lidocaine, $180 \mathrm{~min}$; articaine, $258 \mathrm{~min}$; and bupivacaine, $460 \mathrm{~min}$.

\section{RESULTS}

Ninety subjects were selected and divided into three groups according to the LA used: lidocaine, articaine, or bupivacaine. Table 2 shows the descriptive and 
Table 3. Inferential analysis of adverse effects, stratified according to type of anesthetic used $(\mathrm{n}=90)$

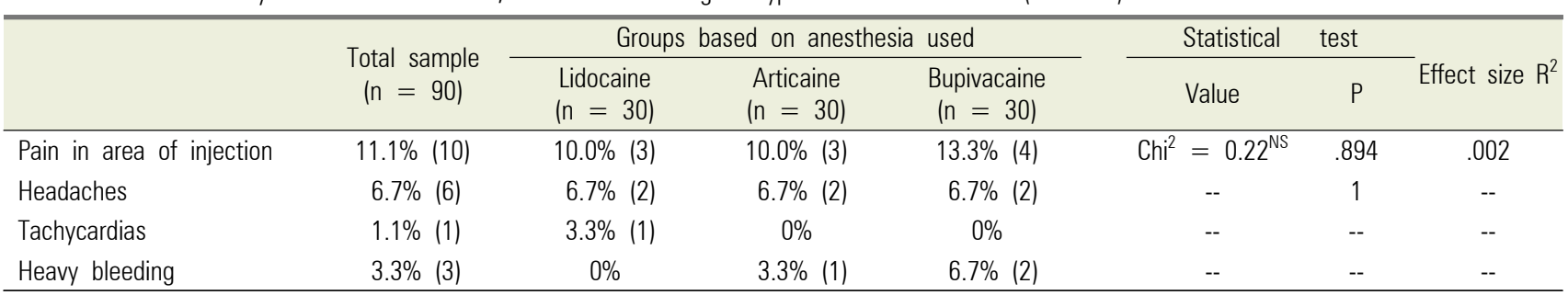

NS, not significant $(P>.05)$.

Table 4. Descriptive analysis of anesthetic effect in the lip

\begin{tabular}{|c|c|c|c|c|c|c|c|c|}
\hline \multirow[b]{2}{*}{ Obs. } & \multirow[b]{2}{*}{ Min. } & \multirow{2}{*}{$\begin{array}{c}\% \text { accumulated } \\
\text { cases } \\
\text { Numbed }\end{array}$} & \multirow{2}{*}{$\begin{array}{c}\text { Tingling } \\
\% \text { of cases over } \\
n=90\end{array}$} & \multirow{2}{*}{$\begin{array}{c}\% \text { accumulated } \\
\text { cases } \\
\text { Normal } \\
\text { sensitivity }\end{array}$} & \multicolumn{4}{|c|}{$\begin{array}{c}\% \text { calculated over the number of "active" cases in each moment } \\
\text { of observation }\end{array}$} \\
\hline & & & & & $n$ & Numbed & Tingling & Normal sensitivity \\
\hline $1^{a}$ & 15 & $80(88.9 \%)$ & $10(11.1 \%)$ & -- & 90 & $80(88.9 \%)$ & $10(11.1 \%)$ & -- \\
\hline $2^{\mathrm{a}}$ & 30 & $65(72.2 \%)$ & $23(25.6 \%)$ & $2(2.2 \%)$ & 90 & $65(72.2 \%)$ & $23(25.6 \%)$ & $2(2.2 \%)$ \\
\hline $3^{a}$ & 45 & $51(56.7 \%)$ & $27(30.0 \%)$ & $10(13.3 \%)$ & 88 & $51 \quad(58.0 \%)$ & $27(30.7 \%)$ & $10(11.4 \%)$ \\
\hline $4^{\mathrm{a}}$ & 60 & $39(43.3 \%)$ & $20(22.2 \%)$ & $19(34.4 \%)$ & 78 & $39(50.0 \%)$ & $20(25.6 \%)$ & $19(24.4 \%)$ \\
\hline $5^{a}$ & 75 & $33(36.7 \%)$ & $12(13.3 \%)$ & $14(50.0 \%)$ & 59 & 33 (55.9\%) & 12 (20.3\%) & $14(23.7 \%)$ \\
\hline $6^{\mathrm{a}}$ & 90 & $30(66.7 \%)$ & $9(10.0 \%)$ & $6(56.7 \%)$ & 45 & $30(66.7 \%)$ & $9(20.0 \%)$ & $6(13.3 \%)$ \\
\hline $7^{a}$ & 105 & $29(32.2 \%)$ & $8(8.9 \%)$ & $2(58.9 \%)$ & 39 & $29(74.4 \%)$ & $8(20.5 \%)$ & $2(5.1 \%)$ \\
\hline $8^{a}$ & 120 & $26(28.9 \%)$ & $7(7.8 \%)$ & $4(63.3 \%)$ & 37 & $26(70.3 \%)$ & 7 (18.9\%) & $4(10.8 \%)$ \\
\hline$g^{a}$ & 135 & $26(28.9 \%)$ & $3(3.3 \%)$ & $4(67.8 \%)$ & 33 & $26(78.8 \%)$ & $3(9.1 \%)$ & $4(12.1 \%)$ \\
\hline $11^{a}$ & 165 & $26(28.9 \%)$ & $2(2.2 \%)$ & -- & 28 & 26 (92.9\%) & $2(7.1 \%)$ & -- \\
\hline $12^{a}$ & 180 & $25(27.8 \%)$ & $2(2.2 \%)$ & $1(70.0 \%)$ & 28 & $25(89.3 \%)$ & $2(7.1 \%)$ & $1(3.6 \%)$ \\
\hline $13^{\mathrm{a}}$ & 195 & $24(26.7 \%)$ & $3(3.3 \%)$ & -- & 27 & $24(88.9 \%)$ & $3(11.1 \%)$ & -- \\
\hline $14^{\mathrm{a}}$ & 210 & $18(20.0 \%)$ & $9(9.0 \%)$ & -- & 27 & $18(66.7 \%)$ & $9(33.3 \%)$ & -- \\
\hline $15^{\mathrm{a}}$ & 225 & $13(14.4 \%)$ & $10(11.1 \%)$ & $4(74.4 \%)$ & 27 & $13(48.1 \%)$ & $10(37.0 \%)$ & $4(14.8 \%)$ \\
\hline $16^{a}$ & 240 & $11(12.2 \%)$ & $6(6.7 \%)$ & $6(81.1 \%)$ & 23 & 11 (47.8\%) & $6(26.1 \%)$ & $6(26.1 \%)$ \\
\hline $17^{a}$ & 255 & $6(6.7 \%)$ & $8(8.9 \%)$ & $3(84.4 \%)$ & 17 & $6(35.3 \%)$ & $8(47.1 \%)$ & $3(17.6 \%)$ \\
\hline $18^{a}$ & 270 & $4(4.4 \%)$ & $4(4.4 \%)$ & $6(91.1 \%)$ & 14 & $4(28.6 \%)$ & $4(28.6 \%)$ & $6(42.9 \%)$ \\
\hline $19^{a}$ & 285 & $1(1.1 \%)$ & $5(5.6 \%)$ & 2 (93.3\%) & 8 & $1(12.5 \%)$ & $5(62.5 \%)$ & $2(25.0 \%)$ \\
\hline $20^{a}$ & 300 & -- & $1(1.1 \%)$ & $5(98.9 \%)$ & 6 & -- & $1(16.7 \%)$ & $5(83.3 \%)$ \\
\hline $21^{a}$ & 315 & -- & -- & 1 (100\%) & 1 & -- & -- & 1 (100\%) \\
\hline
\end{tabular}

comparative analyses of the treatment performed, stratified according to the type of anesthetic used. Additionally, the quadrant and time of administration of phentolamine mesylate after treatment completion have been provided.

The headings of the columns are not clear; if you provide a clarification, I'd be happy make the necessary changes.

Table 3 shows the inferential analysis of the adverse effects, stratified according to the type of LA $(n=90)$. Tachycardia and heavy bleeding were uncommon (one and three cases, respectively). Headaches were reported by six patients $\left(6.7 \%\right.$; $95 \%$ confidence interval $[\mathrm{CI}]: 1.4^{-}$ $11.9 \%)$, which was significant $(\mathrm{P}=0.013)$. Further, when groups were compared using the Chi-square test, the exact same cases were noted for the three groups. Therefore, these adverse effects could not be attributed to a lack of effectiveness of the reversal agent. Finally, the most common adverse effect was pain at the injection site. This was reported by $11.1 \%$ of patients $\left(10 ; 95 \%\right.$ CI: $4.5^{-}$ $13.3 \%)$, which was highly significant $(\mathrm{P}=0.001)$. Similar results were noted for all three groups $(10 \%-13.3 \%)$. Therefore, this adverse effect could not be significantly 
Table 5. Descriptive analysis of anesthetic effect in the tongue

\begin{tabular}{|c|c|c|c|c|c|c|c|c|}
\hline \multirow[b]{2}{*}{ Obs. } & \multirow[b]{2}{*}{ Min. } & \multirow{2}{*}{$\begin{array}{c}\% \text { accumulated } \\
\text { cases } \\
\text { Numbed }\end{array}$} & \multirow{2}{*}{$\begin{array}{c}\text { Tingling } \\
\% \text { of cases over } \\
n=90\end{array}$} & \multirow{2}{*}{$\begin{array}{c}\% \text { accumulated } \\
\text { cases } \\
\text { Normal sensitivity }\end{array}$} & \multicolumn{4}{|c|}{$\begin{array}{c}\% \text { calculated over the number of "active" cases in each } \\
\text { moment of observation }\end{array}$} \\
\hline & & & & & $n$ & Numbed & Tingling & Normal sensitivity \\
\hline $1^{a}$ & 15 & $76(84.4 \%)$ & $14(15.6 \%)$ & -- & 90 & 76 (84.4\%) & $14(15.6 \%)$ & -- \\
\hline $2^{a}$ & 30 & $50(55.6 \%)$ & $38(42.2 \%)$ & $2(2.2 \%)$ & 90 & $50(55.6 \%)$ & $38(42.2 \%)$ & $2(2.2 \%)$ \\
\hline $3^{a}$ & 45 & $45(50.0 \%)$ & $22(24.4 \%)$ & $21(25.6 \%)$ & 88 & $45(51.1 \%)$ & $22(25.0 \%)$ & 21 (23.9\%) \\
\hline $4^{a}$ & 60 & 35 (38.9\%) & $16(17.8 \%)$ & $16(43.3 \%)$ & 67 & $35(52.2 \%)$ & $16(23.9 \%)$ & $16(23.9 \%)$ \\
\hline $5^{a}$ & 75 & 31 (34.4\%) & $13(14.4 \%)$ & 7 (51.1\%) & 51 & 31 (60.8\%) & $13(25.5 \%)$ & 7 (13.7\%) \\
\hline $6^{a}$ & 90 & $27(30.0 \%)$ & $11(12.2 \%)$ & $6(57.8 \%)$ & 44 & $27(61.4 \%)$ & $11(25.0 \%)$ & $6(13.6 \%)$ \\
\hline $7^{a}$ & 105 & $26 \quad(28.9 \%)$ & $7(7.8 \%)$ & $5(63.3 \%)$ & 38 & $26(68.4 \%)$ & 7 (18.4\%) & $5(13.2 \%)$ \\
\hline $8^{a}$ & 120 & $23(25.6 \%)$ & 7 (7.8\%) & $3(66.7 \%)$ & 33 & $23(69.7 \%)$ & 7 (21.2\%) & $3(9.1 \%)$ \\
\hline$g^{a}$ & 135 & $23(25.6 \%)$ & $3(3.3 \%)$ & $4(71.1 \%)$ & 30 & $23(76.7 \%)$ & $3(10.0 \%)$ & $4(13.3 \%)$ \\
\hline $10^{\mathrm{a}}$ & 150 & $23(25.6 \%)$ & 1 (1.1\%) & $2(73.3 \%)$ & 26 & $23(88.5 \%)$ & 1 (3.8\%) & $2(7.7 \%)$ \\
\hline $11^{\mathrm{a}}$ & 165 & $23(25.6 \%)$ & $1(1.1 \%)$ & -- & 24 & $23(95.8 \%)$ & 1 (4.2\%) & -- \\
\hline $12^{\mathrm{a}}$ & 180 & $22(24.4 \%)$ & $1(1.1 \%)$ & $1(74.4 \%)$ & 24 & $22(91.7 \%)$ & 1 (4.2\%) & $1(4.2 \%)$ \\
\hline $13^{a}$ & 195 & $15(16.7 \%)$ & $8(8.9 \%)$ & -- & 23 & $15(65.2 \%)$ & 8 (34.8\%) & -- \\
\hline $14^{\mathrm{a}}$ & 210 & $10(11.1 \%)$ & $8(8.9 \%)$ & $5(80.0 \%)$ & 23 & $10(45.3 \%)$ & $8(34.8 \%)$ & $5(21.7 \%)$ \\
\hline $15^{\mathrm{a}}$ & 225 & $8(8.9 \%)$ & $4(4.4 \%)$ & $6(86.7 \%)$ & 18 & $8(44.4 \%)$ & $4(22.2 \%)$ & $6(33.3 \%)$ \\
\hline $16^{\mathrm{a}}$ & 240 & $6(6.7 \%)$ & $2(2.2 \%)$ & 4 (91.1\%) & 12 & $6(50.0 \%)$ & 2 (16.7\%) & 4 (33.3\%) \\
\hline $17^{a}$ & 255 & $3(3.3 \%)$ & $5 \quad(5.6 \%)$ & -- & 8 & $3(37.5 \%)$ & $5(62.5 \%)$ & -- \\
\hline $18^{a}$ & 270 & $2(2.2 \%)$ & $2(2.2 \%)$ & $4(95.6 \%)$ & 8 & $2(25.0 \%)$ & $2(25.0 \%)$ & $4(50.0 \%)$ \\
\hline $19^{a}$ & 285 & -- & $3(3.3 \%)$ & 1 (96.7\%) & 4 & -- & $3(75.0 \%)$ & $1(25.0 \%)$ \\
\hline $20^{a}$ & 300 & -- & -- & $3(100 \%)$ & 3 & -- & -- & $3(100 \%)$ \\
\hline
\end{tabular}

correlated with the use of the reversal agent with a specific LA ( $\mathrm{P}>0.05)$.

Table 4 shows the descriptive analysis of the total duration of anesthesia in the lip. The differences among the three groups were highly significant $(\mathrm{P}<0.001)$, both when overall or pair-wise

The headings of the columns are not clear; if you provide a clarification, I'd be happy make the necessary changes. comparisons were performed. The average duration of anesthesia was lowest for Group 1 (approximately $60 \mathrm{~min}$ ). The average duration for Group 2 was approximately $90 \mathrm{~min}$. One active case was noted, listed at the end of Table 4. The greatest difference was observed in Group 3, with the average duration of anesthesia being 250-255 min. These results were highly significant and considerably higher than those of the other two groups (difference of $84.3 \%$ ), clearly demonstrating the differences in the effect of reversal agent when combined with different LAs.

Table 5 shows the descriptive analysis of the total duration of anesthesia in the tongue. The average duration of anesthesia was lowest in Group 1 (45-52 $\mathrm{min})$. The duration was significantly longer in Group 2 (75-85 min). Another active case was found, reported at the end of Table 5. The most significant difference was observed in Group 3, with the duration of anesthesia being 214-225 min. The effect size was also higher for this group (difference of $73.9 \%$ ) but was lower than that observed in the lip for the same LA. Nevertheless, differences among the groups were clearly demonstrated.

All patients $(90,100 \%)$ expressed that they would prefer not to feel any numbness after treatment. Consequently, they believed that the anesthesia reversal agent would be beneficial. When asked whether they would recommend phentolamine mesylate to other people, 89 of 90 participants (98.9\%) answered positively.

Table 6 shows the inferential analysis of the difference in the duration of anesthesia for each group $(n=30)$ and the corresponding normative values. In Group 1, the average time taken for anesthesia to wear off in the lip 
Table 6. Inferential analysis of the differences in duration of anesthesia in each group [stratified according to type of anesthetic used (n $=30$ )] and corresponding normative values

\begin{tabular}{|c|c|c|c|c|c|c|c|}
\hline \multirow[b]{2}{*}{ Group 1} & \multirow{2}{*}{ Median } & \multirow{2}{*}{ Mean (D.E.) } & \multirow{2}{*}{ Test value } & \multicolumn{2}{|c|}{ T-Student test } & \multicolumn{2}{|c|}{$95 \%$ C. I } \\
\hline & & & & Value & $\mathrm{P}$ value & Upper limit & Lower limit \\
\hline Duration of anesthesia in the lip & 60.00 & $59.60(12.13)$ & 180 & $-54.41^{*}$ & $<0.001$ & -125.03 & -115.97 \\
\hline Duration of anesthesia in the tongue & 45.00 & $52.50(13.50)$ & 180 & $-51.72^{*}$ & $<0.001$ & -132.54 & -122.46 \\
\hline \multirow[b]{2}{*}{ Group 2} & \multirow{2}{*}{ Median } & \multirow{2}{*}{ Mean (D.E.) } & \multirow{2}{*}{ Test value } & \multicolumn{2}{|c|}{ T-Student Test } & \multicolumn{2}{|c|}{ 95\% C.I } \\
\hline & & & & Value & $P$ value & Upper limit & Lower limit. \\
\hline Duration of anesthesia in the lip & 90.0 & $88.5(33.97)$ & 258 & $-27.33^{*}$ & $<0.001$ & -182.18 & -156.82 \\
\hline Duration of anesthesia in the tongue & 75.0 & $84.5(32.36)$ & 258 & $-29.37^{*}$ & $<0.001$ & -185.58 & -161.42 \\
\hline \multirow[b]{2}{*}{ Group 3} & \multirow{2}{*}{ Median } & \multirow{2}{*}{ Mean (D.E.) } & \multirow{2}{*}{ Test value } & \multicolumn{2}{|c|}{ T-Student Test } & \multicolumn{2}{|c|}{$95 \%$ C.I } \\
\hline & & & & Value & $P$ value & Upper limit. & Lower limit \\
\hline Duration of anesthesia in the lip & 255.0 & $249.0(52.05)$ & 460 & $-22.20^{*}$ & $<0.001$ & -230.44 & -191.56 \\
\hline Duration of anesthesia in the tongue & 225.0 & $214.5(64.51)$ & 460 & $-20.85^{*}$ & $<0.001$ & -269.59 & -221.41 \\
\hline
\end{tabular}

$\mathrm{Cl}$, confidence interval; D.E., difference.

* Highly significant $(\mathrm{P}<.01)$

(59.6 $\mathrm{min})$ and tongue $(52.5 \mathrm{~min})$ was lower than the normative value $(180 \mathrm{~min})$; these differences were highly significant $(\mathrm{P}<0.001)$. Therefore, there was a reduction of $116^{-125} \mathrm{~min}(95 \% \mathrm{CI})$ in the lip and $122-132 \mathrm{~min}$ (95\% CI) in the tongue for lidocaine. In Group 2, the average durations of anesthesia in both the lip $(88.5 \mathrm{~min})$ and tongue $(84.5 \mathrm{~min}$ ) were significantly lower than the determined normative value $(258 \mathrm{~min} ; \mathrm{P}<0.001)$, with larger effect sizes (approximately 97\% for each variable). Therefore, there was a reduction in duration of anesthesia of 157-182 $\min (95 \% \mathrm{CI})$ in the lip and 161-185 $\mathrm{min}$ $(95 \% \mathrm{CI})$ in the tongue Your meaning is not clear here. Please provide the full form of the abbreviation here. for the articaine group, which was higher than that reported in the lidocaine group. Similarly, in Group 3, the average durations of anesthesia in the lip (249 min) and tongue (214 min) were much lower than the calculated normative value (460 min). Therefore, these differences were highly significant $(P<0.001)$ with large effect sizes (over 97\% for each variable), indicating that the reversal agent was highly effective. There was a reduction in the duration of anesthesia of $192-230 \mathrm{~min}(95 \% \mathrm{CI})$ in the lip and $221-270 \min (95 \% \mathrm{CI})$ in the tongue in the bupivacaine group, which was greater than the reduction observed in the other groups.

\section{DISCUSSION}

The reversal agent reduced the duration of anesthesia of 116-125 $\mathrm{min}$ in the lip and 122-132 $\mathrm{min}$ in the tongue in Group 1. Laviola et al. [2] reported an improvement in patients' perception of numbing sensation in the lower lip and tongue with phentolamine mesylate: a reduction of $47 \mathrm{~min}$ in the duration of anesthesia in the lower lip and $54.5 \mathrm{~min}$ in the tongue in the group treated with lidocaine with epinephrine. Similar results have been shown in a study by Michaud et al. [22].

In Group 2, the average duration of anesthesia was lowered by $157-182 \mathrm{~min}$ in the lip and 161-185 $\mathrm{min}$ in the tongue. Laviola et al.[2] reported reductions of 42.5 $\mathrm{min}$ in the lip and $12.5 \mathrm{~min}$ in the tongue for the articaine group. Hersh et al. [23] found a reduction of $85 \mathrm{~min}$ in the lower lip and $65 \mathrm{~min}$ in the tongue. Fowler et al. [24] obtained a reduction of $47 \mathrm{~min}$ in the lower lip and $27 \mathrm{~min}$ in the tongue. In a meta-analysis, Prados-Frutos et al. [25] compared several similar studies that reported reductions in the same parameters. The results obtained here show that the reduction in the duration of anesthesia for the lidocaine and articaine groups were higher than those from previous studies.

In Group 3, there was a reduction of $192-230 \mathrm{~min}$ in the lip and 221-270 $\mathrm{min}$ in the tongue. Therefore, the 
reversal agent reduced the overall duration of anesthesia by $3-4 \mathrm{~h}$, which was greater than that reported in the other two groups. Michaud et al. reported that $0.5 \%$ bupivacaine and 1:200000 epinephrine reduced the average duration of anesthesia by $2 \mathrm{~h}$ and $17 \mathrm{~min}$ [26]. Active cases (end of Tables 4 and 5) are probably due to a lack of efficiency of the investigators when administering the reversal agent or its accumulation in the wrong location. This is also common with the inferior alveolar nerve blocking technique, as seen in several studies on the efficacy of local anesthesia techniques [2730].

Adverse effects reported here were similar to those reported in previous studies on the safety of phentolamine mesylate such as the study by Daubländer et al. [8]. Overall, these effects are uncommon and clinically insignificant $[9,11,25,31,32]$. One potential complication is postoperative bleeding due to vasodilatation caused by phentolamine mesylate. Froum et al. [33] also used phentolamine mesylate to evaluate possible damage to the inferior alveolar nerve immediately after implant surgery. In the present study Your meaning is not clear here. If you provide a clarification, I can make the appropriate changes., we observed that in treatments in which patients could potentially bleed, heavy bleeding occurred in only $3.3 \%$ of cases.

All patients reported a preference of no residual sensation of anesthesia after treatment, and $98.9 \%$ of participants would recommend phentolamine mesylate to other people. Similar results were reported by Shetty et al. [34]. However, dentists may be reluctant to use it for common dental treatments due to the additional cost of phentolamine mesylate [35].

All previous studies on the effectiveness of phentolamine mesylate as a reversal agent for local anesthesia have used lidocaine and articaine combined with a vasoconstrictor, but no study has been conducted using bupivacaine. For interventions expected to last longer than usual, using anesthetics with a longer duration is preferable to administering multiple doses, which may cause toxicity [36].
Nevertheless, usage of bupivacaine is consistently decreasing in dentistry due to its excessive latency compared to other anesthetics, cardiotoxicity, and prolonged duration of action after treatment [37,38]. However, Gonca and Çatlı [39] showed that the combination of lidocaine (with epinephrine) and bupivacaine not only produced a longer duration of anesthesia, but also had a protective effect on the cardiotoxicity caused by bupivacaine. Moreover, the higher $\mathrm{pKa}$ of the bupivacaine and lidocaine combination prevented delayed onset of action of bupivacaine [40].

In summary, the present results show that when used as a reversal agent for LAs, phentolamine mesylate decreases the overall duration of anesthetic effect, producing a significant improvement when combined with bupivacaine.

This study had some limitations. There was no true 'control group', in which phentolamine mesylate was not administered. Furthermore, some parameters of the patient questionnaire could vary based on the dental therapy (simple restorative versus invasive treatment). Additionally, whether the adverse effects were attributable to LA or phentolamine mesylate was unclear. Therefore, future investigations with a control group are needed.

In conclusion, phentolamine mesylate can reduce the duration of anesthesia in combination with different LAs, with an especially significant reduction with bupivacaine. Potential adverse effects are uncommon. Patients reported a high degree of satisfaction and would recommend the treatment. Phentolamine mesylate could be a good option for decreasing postoperative complications caused by anesthesia and shortening the duration of residual anesthetic sensations after a dental intervention.

\section{AUTHOR ORGDS}

\footnotetext{
Alejandro Gago Garcia: https://orcid.org/0000-0002-2635-7548

Cayetana Barrilero Martin: https://orcid.org/0000-0002-3137-9135

Miguel Angel Alobera Gracia: https://orcid.org/0000-0001-6621-2186

Mariano del Canto Pingarrón: https://orcid.org/0000-0001-6267-2687

Jesus Seco Calvo: https://orcid.org/0000-0002-7818-9777
} 


\section{AUHOR CONHRIBUIONS}

Alejandro Gago Garcia: Conceptualization, Data curation, Investigation, Methodology, Software

Cayetana Barrilero Martin: Formal analysis, Writing - review \& editing Miguel Angel Alobera Gracia: Visualization, Writing - review \& editing Mariano del Canto Pingarrón: Project administration, Resources, Writing - review \& editing

Jesus Seco Calvo: Software, Supervision, Validation, Visualization, Writing - review \& editing

DECLARATION OF INTEREST: This research did not receive any specific grant from any public, commercial, or not-for-profit agencies.

\section{REFERENCES}

1. Becker DE, Reed KL. Local anesthetics: review of pharmacological considerations. Anesth Prog 2012; 59: 90-101.

2. Laviola M, McGavin SK, Freer GA, Plancich G, Woodbury SC, Marinkovich S, et al. Randomized study of phentolamine mesylate for reversal of local anesthesia. J Dent Res 2008; 87: 635-9.

3. Nourbakhsh N, Shirani F, Babaei M. Effect of phentolamine mesylate on duration of soft tissue local anesthesia in children. J Res Pharm Pract 2012; 1: 55-9.

4. Rutherford B, Zeller JR, Thake D. Local and systemic toxicity of intraoral submucosal injections of phentolamine mesylate (OraVerse). Anesth Prog 2009; 56: 123-7.

5. Grover HS, Gupta A, Saksena N, Saini N. Phentolamine mesylate: It's role as a reversal agent for unwarranted prolonged local analgesia. J Indian Soc Pedod Prev Dent 2015; 33: 265-8.

6. Saunders TR, Psaltis G, Weston JF, Yanase RR, Rogy SS, Ghalie RG. In-practice evaluation of OraVerse for the reversal of soft-tissue anesthesia after dental procedures. Compend Contin Educ Dent 2011; 32: 58-62.

7. Hersh EV, Lindemeyer R, Berg JH, Casamassimo PS, Chin J, Marberger A, et al. Phase Four, Randomized, DoubleBlinded, Controlled Trial of Phentolamine Mesylate in Two- to Five-year-old Dental Patients. Pediatr Dent 2017;
15; 39: 39-45.

8. Daubländer M, Liebaug F, Niedeggen G, Theobald K, Kürzinger ML. Effectiveness and safety of phentolamine mesylate in routine dental care. J Am Dent Assoc 2017; 148: $149-56$

9. Donaldson M, Goodchild JH. Pharmacological reversal agents in dental practice: keys to patient safety. Compend Contin Educ Dent 2016; 37: 681-7.

10. Elmore S, Nusstein J, Drum M, Reader A, Beck M, Fowler S. Reversal of pulpal and soft tissue anesthesia by using phentolamine: a prospective randomized, single-blind study. J Endod 2013; 39: 429-34.

11. Boynes SG, Riley AE, Milbee S, Bastin MR, Price ME, Ladson A. Evaluating complications of local anesthesia administration and reversal with phentolamine mesylate in a portable pediatric dental clinic. Gen Dent 2013; 61: 70-6.

12. Prasanna JS. OraVerse: reverses numbness after dental procedures. J Maxillofac Oral Surg 2012; 11: 212-9.

13. Moore PA, Hersh EV, Papas AS, Goodson JM, Yagiela JA, Rutherford B. Pharmacokinetics of lidocaine with epinephrine following local anesthesia reversal with phentolamine mesylate. Anesth Prog 2008; 55: 40-8.

14. Hersh EV, Moore PA, Saraghi M. Phentolamine mesylate: pharmacology, efficacy, and safety. Gen Dent 2019; 67: 12-7.

15. Tavares M, Goodson JM, Studen-Pavlovich D, Yagiela JA, Navalta LA, Rogy S, et al. Reversal of soft-tissue local anesthesia with phentolamine mesylate in pediatric patients. J Am Dent Assoc 2008; 139: 1095-104.

16. Faul F, Erdfelder E, Lang AG, Buchner A. G*Power 3: a flexible statistical power analysis program for the social, behavioral, and biomedical sciences. Behav Res Methods 2007; 39: 175-91.

17. Calvo-Lobo C, Almazán-Polo J, Becerro-de-BengoaVallejo R, Losa-Iglesias ME, Palomo-López P, Rodríguez-Sanz D, et al. Ultrasonography comparison of diaphragm thickness and excursion between athletes with and without lumbopelvic pain. Phys Ther Sport 2019; 37: 128-37.

18. Heft MW, Parker SR. An experimental basis for revising 
the graphic rating scale for pain. Pain 1984; 19: 153-61.

19. Trullenque-Eriksson A, Guisado-Moya B. Comparative study of two local anesthetics in the surgical extraction of mandibular third molars: bupivacaine and articaine. Med Oral Patol Oral Cir Bucal 2011; 16: e390-6.

20. Gregorio LV, Giglio FP, Sakai VT, Modena KC, Colombini BL, Calvo AM, et al. A comparison of the clinical anesthetic efficacy of $4 \%$ articaine and $0.5 \%$ bupivacaine (both with 1:200,000 epinephrine) for lower third molar removal. Oral Surg Oral Med Oral Pathol Oral Radiol Endod 2008; 106: 19-28.

21. Fernandez C, Reader A, Beck M, Nusstein J. A prospective, randomized, double-blind comparison of bupivacaine and lidocaine for inferior alveolar nerve blocks. J Endod 2005; 31: 499-503.

22. Michaud PL, Flood B, Brillant MS. Reversing the effects of 2\% Lidocaine: A randomized controlled clinical trial. J Dent 2018; 72: 76-9.

23. Hersh EV, Moore PA, Papas AS, Goodson JM, Navalta LA, Rogy S, et al. Reversal of soft-tissue local anesthesia with phentolamine mesylate in adolescents and adults. J Am Dent Assoc 2008; 139: 1080-93

24. Fowler S, Nusstein J, Drum M, Reader A, Beck M. Reversal of soft-tissue anesthesia in asymptomatic endodontic patients: a preliminary, prospective, randomized, single-blind study. J Endod 2011; 37: 1353-8.

25. Prados-Frutos JC, Rojo R, González-Serrano J, González-Serrano C, Sammartino G, Martínez-González JM, et al. Phentolamine mesylate to reverse oral soft-tissue local anesthesia: A systematic review and meta-analysis. J Am Dent Assoc 2015; 146: 751-9

26. Michaud PL, Nowe E, Smith Brillant M. Reversing the effects of $0.5 \%$ bupivacaine using phentolamine mesylate: a preliminary randomized controlled clinical trial. J Clin Pharmacol 2020.

27. Kriangcherdsak Y, Raucharemporn S, Chaiyasamut T, Wongsirichat N. Success rates of the first inferior alveolar nerve block administered by dental practitioners. J Dent Anesth Pain Med 2016; 16: 111-6.

28. Sawadogo A, Coulibaly M, Quilodran C, Bationo R, Konsem T, Ella B. Success rate of first attempt $4 \%$ articaine para-apical anesthesia for the extraction of mandibular wisdom teeth. J Stomatol Oral Maxillofac Surg 2018; 119: 486-8.

29. Alhindi M, Rashed B, AlOtaibi N. Failure rate of inferior alveolar nerve block among dental students and interns. Saudi Med J 2016; 37: 84-9.

30. Gazal G. Overcoming the failure of anesthesia in the mandibular teeth. Saudi Med J 2019; 40: 425.

31. Vinnakota DN, Kamatham R. Safety profile of phentolamine mesylate as reversal agent of pulpal and soft tissue dental anesthesia: a systematic review and meta-analysis. Quintessence Int 2019; 50: 568-75.

32. Helmi M, AlDosari M, Tavares M. Phentolamine mesylate may be a safe and effective option to reduce discomfort and time to recovery after dental care with local anesthesia. J Evid Based Dent Pract 2018; 18: 181-4.

33. Froum SJ, Froum SH, Malamed SF. The use of phentolamine mesylate to evaluate mandibular nerve damage following implant placement. Compend Contin Educ Dent 2010; 31: 520, 522-8.

34. Shetty C, Devanathan N, Shetty A, Shetty S, Hegde MN. Phentolamine mesylate as a drug for reversal of local anaesthesia --a questionnaire based study. J Evol Med Dent Sci 2020; 43: 3227-30.

35. Yagiela JA. What's new with phentolamine mesylate: a reversal agent for local anaesthesia? SAAD Dig 2011; 27: 3-7.

36. Malamed SF. Modern dental pain control. Dent Today 2008; 27: 72, 74, 76-7.

37. Dillane D, Finucane BT. Local anesthetic systemic toxicity. Can J Anaesth 2010; 57: 368-80.

38. Butterworth JF 4th. Models and mechanisms of local anesthetic cardiac toxicity: a review. Reg Anesth Pain Med 2010; 35: 167-76.

39. Gonca E, Çath D. The effects of lidocaine with epinephrine on bupivacaine-induced cardiotoxicity. Turk J Anaesthesiol Reanim 2018; 46: 447-52.

40. Powell MF, Jarzombek KW, Venhuizen KJ, Tubinis MD, Morgan CJ, Frölich MA. Comparing bupivacaine, lidocaine, and a combination of bupivacaine and lidocaine for labor epidural activation: a prospective, randomized, double-blind study. Asian J Anesthesiol 2019; 57: 55-60. 